\title{
Prospects of Nanotechnology in Bangladesh Perspective
}

\author{
Ashfaq Iftakher and Ahaduzzaman*
}

Department of Chemical Engineering, Bangladesh University of Engineering and Technology (BUET), Dhaka-1000, Bangladesh *Email: chenahid@gmail.com

\begin{abstract}
Nanotechnology brings huge promise in the research and development in industrial sectors to increase the efficiency and productivity. It deals with matters at as small as billionth of a meter scale. At this nano scale, the physiochemical properties of matter dramatically change due to quantum confinement. So there are huge possibilities in developing applications by harnessing the nano scaled physiochemical properties of nano materials in numerous fields. Bangladesh, being a developing country lacks the proper guideline and investment to take advantage of this technology. Nanotechnology has a huge prospect in this country especially in agriculture and garments sector. If applied properly, nanotechnology can boost the economic growth as well as improve the capacity and quality in agriculture, food and other industrial sectors. This paper describes the current status of Nanotech research and development, applications in major industrial sectors, future prospects in the context of Bangladesh. This paper also discusses the safety, risks and challenges associated with nanotech and provide a general guideline and recommendations for the application of nanotechnology in major industrial sectors of Bangladesh.
\end{abstract}

Keywords: Nanotechnology; Prospects; Quantum confinement; Nano material

\section{Introduction}

Nanotechnology is a technology of the future that has the capability to influence numerous engineering fields and industries. It is an atomic or molecular level technology that harnesses the interesting properties of matter at the nanoscale. A particle is called a nanoparticle if at least one of its dimensions is between 1 and 100 nanometers. The properties of a matter such as mechanical, optical, magnetic and electronic properties at the macro scale is different than at nano scale due to quantum confinement. This is because electrons cannot move easily at the dimensions as small as billionth of a meter. Surface area also increases rapidly as the dimensions go down. Nanotechnology takes advantage of such size dependent properties such as sorption and catalytic activity [1-3]. Inventions regarding Nanotech show promises of revolutionary industrial wave. Higher catalytic activity of a material at nano scales concerns are raised for the usage in health and food sectors. In this paper, applications of nanotechnology in food, waste water treatment, agriculture, health, textiles and cosmetics sectors are discussed. Developed countries are already taking advantage of Nanotech in these fields. Being a developing country, Bangladesh's economy largely depends on agriculture and industrial sectors. So Bangladesh can be greatly benefitted if Nanotech can be used to improve quality, efficiency and productivity in different sectors. The current study discusses the potential application of Nanotech in context of Bangladesh. Some of the applications are already at play while some others are still at experimental phase. This paper discusses the challenges that need to be overcome to properly utilize the potentials and recommends a general guideline to be followed in a developing country like Bangladesh.

\section{Application of Nanotechnology}

Nanotechnology is a greatly interdisciplinary field which can influence numerous sectors in the most unexpected and exciting ways. Materials exhibit mind blowing properties at the nanoscales which reveal opportunities and ideas to be implemented in a new way. This leads newer application to already existing industries. The applications of nanotechnology in a few selected major industrial sectors are described below:

\subsection{Nanotechnology in Agriculture}

Nanotechnology can immensely influence agricultural science which will subsequently increase food production exponentially. Due to over use of land, fertility declined. Crop yield stagnated because of declining organic matter. Scarcity of water availability is already visible to many areas. Present day agricultural scientists can use nanotechnology to tackle such problems. Nano fertilizers should be given maximum emphasis as fertilizers increase food production to $35 \%-40 \%$. Depending on the requirement of crops, nanofertilizers regulate the release of nutrients which can increase nutrient use efficiency [4]. A patented nano-composite consisting of Nitrogen, phosphorus, potassium and other micronutrients have shown to increase the uptake and utilization of nutrients by

\footnotetext{
* Corresponding author: Ahaduzzaman

Email: chenahid@gmail.com
} 
grain crops [5]. Another improvement includes a low release phosphatic fertilizer by using zeolites as carriers. Nano membranes can be used as fertilizer coatings for slow and steady release of nutrients which can avoid wastage or overdosing.

A comparative study shows that nano fertilizers are capable of releasing nutrients (specially $\mathrm{NO}_{3}-\mathrm{N}$ ) for longer time (generally 50 days) than traditional fertilizers e.g urea which can only provide nutrients for maximum of 12 days [6]. Bio and nano sensors can evaluate soil fertility, pathogen and other pollutants and level of nutrient content with molecular precision [7]. Nano sensors can transmit data of nutrient used by plants during an interval. These data can be evaluated for future use with optimal amount of nutrients.

\subsection{Nanotechnology in food and allied Industry}

The nano food market has grown to $\$ 30.4$ billion in 2015 [11]. Physical example of nanotech in food sector includes fine wheat flour that has greater water binding capacity. Also when green tea powder is reduced to $1000 \mathrm{~nm}$, its antioxidant activity greatly improves. Food industries mainly use Nanotech in the form of nanocapsules and nanodispersions. Nanotechnology has a huge promise to be used in food sectors as food additives where nanoparticles are mixed with the food product to increase its nutrition content, physical color and functionality [8]. Nanotechnology can also be used in food packaging where nano particles are used outside of the main food product. Nano particles incorporated food packaging ensures greater degree of food safety. Nano wrappers provide smart packaging system that improves foods shelf life, detect and prevent moisture contents, gas leakage and so forth [9]. Food industries can use nano fibers as food matrix for artificial foods. Encapsulation is another interesting technique of Nanotechnology that attracts lots of interest. It is created by nanosized particles that improve absorption, used to target tissues where biologically active substances are needed. Nano particles can also be used for the removal of fat and sugar content. Foods enriched with greater content of sugar or cholesterols can be incorporated with nanomaterials to prevent our digestive system from absorbing elements harmful for cellular or biological developments.

There exists patented food related nano products which include encapsulated materials known as "nanodrop" delivery systems. Chinese nanotea is a nano-based mineral supplement. Among present day mineral supplements nanosilver and nanogold are noteworthy. For improved bio availability, nanoparticles that are dispersible in water called carotenoids can be added to fruit drinks. Nano particles with enhanced mechanical and thermal properties are being used for food packaging that ensures better safety and protection from microbs and bacteria.

Nano sensors can be used for food packaging to detect temperature and moisture content of food products throughout the supply chain [10]. Silicate nanoparticles control oxygen content which is an indicator of internal condition of a food package during product delivery [11]

\subsection{Nanotechnology in health care}

Nanotechnology can be used in medical science to interact with the body at subcellular levels. Nano drugs can be targeted to the specified affected tissues [12]. Drugs coated with nanoparticles can be developed for the desired amount of drug release. Nanotechnology can be used in medicine to achieve maximum therapeutic efficiency. Nano drugs can be developed to ensure minimum side effects as well.

Drugs coated with nano sensors can exploit the difference between normal cells and affected cells. Thus these can be used as site specific drugs. Traditional drugs can't be used in brain due to brain - blood barriers [13-14]. Nanotechnology offers a solution that can efficiently use drugs in brain without affecting the barriers. Capsules made of nano polymers can be designed to discharge drugs at control rates in certain environments [15].

\subsection{Nanotechnology in waste water treatment}

Fresh water is prerequisite and basic need for every human being. The current water supply will decrease to one third within couple of years due to climatic change [16]. The sewage, municipal, industrial and process wastewater should be recycled and can be used after removing the contaminants from the wastewater [1-3]. This will help to fulfill the fresh water demand of a country. Normally waste water is contaminated with bacteria or other type of viruses which cause water-borne diseases. The traditional water treatment technologies like activated carbon, oxidation, reverse osmosis are not so efficient to treat highly polluted water from different industries. Nanotechnology can be a better option for treating the highly polluted water in an efficient way. It reduces the system size as well as energy consumption. There are four different types of Nanomaterials which are used to water purification such as [17]:

- Dendrimers

- metal-containing nanoparticles,

- Zeolites and

- Carbonaceous nanomaterials.

They have some physiochemical activities such as fast dissolution, high reactivity, and strong sorption, super para magnetism, localized surface plasmon 
resonance, and quantum confinement effects which are used to remove the water contaminates including bacteria, viruses, toxic metals, pesticides and salts.

\subsection{Nanotechnology in Textile Industry}

The textile industry is covering a large industrial sector in terms of contribution to gross domestic products and employment. Application of Nanotechnology in this sector increases the product quality. The Nanotechnology should be used to compete the world market in this sector. It can also reduce the production cost; increase the durability of fabrics and its comfortness. There are some particles which are used in textile sector such as:

- Nanocomposite and Carbon fibers: Nanocomposite fibers reduce the chain mobility of the system, increase toughness and abrasion load while carbon nanofibers increase the tensile strength of the composite.

- Clay nanoparticles: Clay nanoparticles are very much resistant to heat. By using this particle in textile can block the UV light, improve tensile modulus, flexural strength and flexural modulus [18]. The nano size titanium dioxide can absorb UV radiation more efficiently than the conventional size. So, it should be used to protect the human being from dangerous UV radiation.

- Nanowhiskers: It is basically a hydrocarbon which is added to the fibers to peach fuzz effect without lowering the cotton strength.

The rapid growth of Nanotechnology is very suitable in this sector. It can significantly change the human life, social environment and country's economy.

\subsection{Application of Nanotechnology in Cosmetics}

According to PEN (Project on Emerging Nanotechnology), nanotechnology products are on the rise. Total amounts increased by nearly $1900 \%$ between 2005 and 2009 from 54 registered products to 1015, respectively [19]. The new EU Cosmetic Products Regulation (nr 1223/2009) defines a cosmetic product that can be used in various external parts of the human body e.g skin, hair, nails, lips, teeth and so forth. Cosmetics are used mainly to clean, perfume or change appearances, and/or protect external parts of a body [20].

Nanotechnology can be incorporated with cosmetics industries for processes i.e formulation, packaging and manufacturing equipment. Zinc oxides and other nano silvers are used as nano particles in cosmetics for packaging, anti-bacterial coatings and air - moisture barriers.
The most common materials used in nanotechnology were silver (299 products), carbon (82 products), titanium/titania (50 products), silicon/silica (35 products), zinc/zinc oxide (30 products), and gold (27 products) [21]. All these materials are present in currently marketed cosmetic products, including sun screens. Nanoparticles used in cosmetics offer the following advantages:

- UV shielding

- Dental care effects

- Insoluble thickening agent

- Enhances optical properties such as skin whitening.

- Increase transparency and reflectivity of cosmetics product.

So, it is important to imply nanotechnology in this sector to take these great advantages.

\section{Recent Development of Nanotechnology in Bangladesh}

There are currently $20-25$ institutions involved in nanotech research in Bangladesh. Bangladesh Atomic Energy Commission (BAEC), Bangladesh Council of Scientific and Industrial Research (BCSIR), National Institute of Biotechnology (NIB), Bangladesh National Scientific and Technical Documentation Centre (BANSDOC), Bangladesh University of Engineering and Technology (BUET) are the major institutes for nanoparticles research [22].

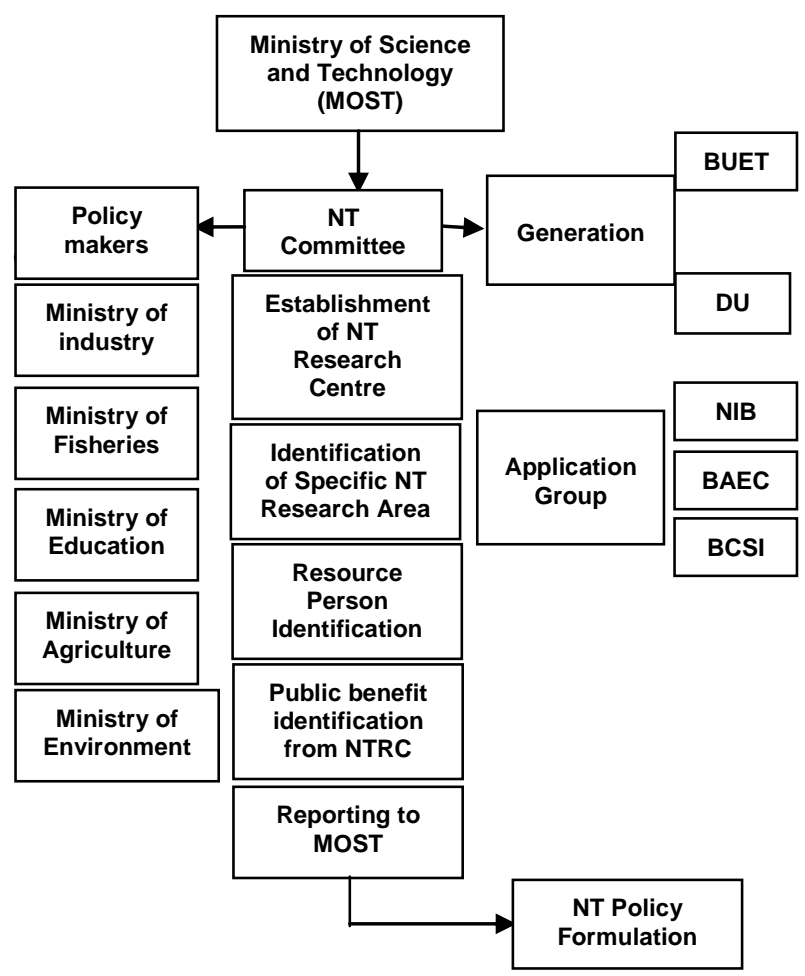

Fig.1.Nanotechnology Policy Framework formulation in Bangladesh [24]. 
Bangladesh Government has taken some initiatives to develop R\&D section of nanotechnology. The nanotechnology (NT) policy formulation framework in Bangladesh is shown in Fig.1.

There is an estimate of at least 50 researchers currently active in Nanotech research in 20-25 fields [22]. Nano particles in the area of agriculture's, packaging, solar cells, fabrics, energy and environment pollution control, and biosensor are being developed. There is an estimation of 30 machineries available for research in nanotech in all the previously stated institutions. Approximately 23.34 million USD were expended by Bangladesh Govt in 2013 - 2014 [22].

\section{Prospects of Nanotech in Bangladesh}

Bangladesh, being still a developing country can benefit immensely if Nanotech can be used properly. The economy of Bangladesh largely depends on agriculture and garments industries. These two fields should be the primary target where Nanotech can be used to rapidly increase production. Nanoparticles can be incorporated with traditional fertilizers to apply on the field that can ensure slow and desired amount of release. This will optimize the total quantity of fertilizers needed which will minimize production costs. In garments factory, Nanoparticles can be used to create fabrics that are water resistant, anti-microbial and UV protected. Bangladesh already has an edge in garments sector due to its availability of cheap labor. So, fabrics with better quality have the potentiality to further stretch the economic expansion of garments and textile sectors of Bangladesh. Many people are still out of electricity in Bangladesh. Best feasible solution is to apply solar powered electricity generators in such areas. Nano particles can be used to create high efficiency semiconductors that can boost solar electricity production exponentially. Nanotech can also be used in Pharmaceuticals industries of Bangladesh. The waste water released by pharmaceuticals can be efficiently treated using nano absorbents. Also, pharmaceuticals can use nanoparticles to produce release controlled drugs.

\section{Risk and challenges in nanotechnology}

It is important to assess the risks associated with any new technology. There has been extensive research on the harmful aspects of nano particles which make researchers cautious about future development of certain promising nano materials. In order for the nanotechnology to be globally accepted, researchers need to find a way to ensure safer use of Nanotech without any possibility of harmful side effects. Below are some of the noteworthy challenges Nanotech has to overcome in order to be wholeheartedly accepted [23].
- Nano particles entering the body may easily travel to organs via blood streams such as heart or liver where presence of such particles is highly unwanted.

- Nano particles being so small in dimensions can easily pass blood - brain barrier which can be deadly if harmful particles travel to the brain.

- Nano particles face no obstacles in cell membranes. So cells can be negatively affected by the presence of unwanted nanoparticles.

- As the properties of matter are extremely dissimilar to its bulky counterpart, effects of many nano particles are still unknown.

- Nano particles can be extremely toxic due to higher order of reactivity. So nano coating used in food packaging or fertilizer can create a negative influence on the product.

- Gold, in bulky form is highly inert whereas nanogold is highly reactive. Such bewildering properties of materials get intensified if combined with iron. These have unknown effects on food, health and environment.

Extensive research must be conducted to establish a list of safe nanoparticles to be used in various industries.

\section{Recommendation of Nanotech in Bangladesh}

It is a common belief that Nanotech needs huge amount of investment in research and development. This is not true for all cases. Many nano materials can be synthesized, identified and characterized using the already existing facilities in Bangladesh e.g Atomic energy commission, Bangladesh University of Engineering and Technology (BUET). Bangladesh government should invest on research and development in Nanotech to produce highly qualified manpower. Prominent industries of Bangladesh should collaborate with countries that are already using nanotech to a great extent of success, bring patented technologies and relevant instruments to hybridize productions. Bangladesh should take long term guidelines focusing on both academic trainings to adequately equip next generation researchers for research and commercialization of nanotech industries.

\section{Conclusion}

Nanotechnology is a very interesting field that can, if applied properly, bring revolutionary change in the engineering and industrial sectors. Developed countries have already embarked on this journey investing huge amount of money for the nanotech research and development of related materials. Many countries are actively using nano materials in numerous industrial sectors and being benefitted. Developing countries are also steadily realizing the 
exciting prospects of nanotechnology and engaging in its research and development. Bangladesh has a bright prospect in nanotechnology as well, especially in agriculture and garments industries. There should be a concrete long term government policy and investment on this technology. However, nanotechnology is not entirely safe for use due to its high catalytic activity. Selective safe use of this exciting technology can boost the production and economy of Bangladesh.

\section{References}

1. Khan E A, Rajendran A, Lai Z, 'Fixed=Bed Adsorption Separation of Xylene Isomers OverSiO $\mathrm{O}_{2}$ /Silicallite-1 Core-Shell Adsorbents', Chemical Engineering Research Buletin, 16, 2013, pp: 1-15.

2. Khan E A, Rajendran A, Lai Z, 'Synthesis of Ni$\mathrm{SiO}_{2} /$ Silicallite-1 Core-Shell Micro-membrane Reactors and their Reaction/Diffusion Performance', Ind. Eng. Chem. Res, 49(24), 2010, pp: $12423-12428$.

3. Khan E A, Rajendran A, Lai Z, 'Preparation of Metal oxide/Zeolite core-shell nanostructures', Micropor. Mesopor. Mater, 118, 2009, pp: 210 217.

4. Liu X, Feng Z, Zhang S, Zhang J, Xiao Q and Wang $Y$,'Preparation and testing of cementing nano-subnano composites of slow or contr5olled release of fertilizers', Scientia, Agriculturl, Sinica, 39, 2006, pp:1598-604.

5. Jinghua G,' Synchrotron radiation, soft X-ray spectroscopy and nano materials', Journal of nano technology, 1,2004,pp:1-21

6. Subramanian $\mathrm{K} S$, Tenshia $\mathrm{V}$ and Jayalakshmik,' Biochemical changes and zinc fractions arbuscularmycorrhizal fungus inoculated and uninoculated soils under differential zinc fertilizetion', Applied soil ecology, 10, 2009, pp:1016-26

7. Subramanian K S and Tarafdar J C, ' Prospects of nanotechnology in indianfarming', Indian journal of agricultural science,81(10), 2011, pp: 887-93

8. Shibata T,' Method for producing green tea in microfine powder', united states patent US6416803B1

9. Richardson N S M and Piehowski K E,' Nanotechnology in nutritional sciencee Minerva', Biotechnol, 20,2008,pp:17-126

10. Sorrentino A G, Gorrasi and VittoriaV,'Potential perspectives of bionano composites for food packaging applications', Trends food SciTechnol ,18.2007, pp: 84-95

11. Afroz $Q M$, Swaminathan $K$, Karthikeyan $P$, Ahmed K P, Sudhir $U$ and Kumar M U,' Application of food and dairy processing', PAK.J. FOOD. SCI, 22(1), 2012, pp:23-31

12. Vasir $\mathrm{J} \mathrm{K}$ and Labhasetwar $\mathrm{V}$,' Targeted drug delivery in cancer therapy', Technol Cancer Res Treat, 4, 2005, pp:363-74

13. Alyautdin R N, Tezikoy E B, Ramge $P$, Kharkevich D A, Begley D J, Kreuter J, 'Significant entry of tubocurarine into the brain of rats by adsorption to polysorbate 80 - coated polybutilecyano acrylate nanoparticals', JMicroencapsul, 15, 1998, pp: 67-74

14. Garcia G E, Gil S, Andrieux K,'A relevant in vitro rat model for the evaluation of blood brain barrier trans location of nano particles', Cell Mol Life Sci,62,2005,pp:1400-8

15. Sahoo S K, parveen S, Panda M S J J, ' The present and future of nanotechnology in human health care', Nanomedicine: nanotechnology, Biology and medicine, 3,2007,pp:20-31

16. Vorosmarty C J, green P, Salisbury J, Lammers $R$ B,'Global water resources: vulnerability from climate changes and population growth', Science, 289(5477),2000,pp:284-288

17. SulekhaMs,' Nanotechnology for waste water treatment', P-ISSN2349-8528, E-ISSN, 23214902, IJCS, 4,2,2016,pp:22-24

18. Patra J K and Gouda S, 'Application of nanotechnology in textile engineering', Journal of engineering and technology, 5,5,2013,pp:104-111

19. http://www.nanotechproject.org/inventories/cons umer/analysis_draft/.

20. http://eurlex.europa.eu/LexUriServ/LexUriServ.d o?uri=OJ:L:2009:342:0059:0209:en:PDF.

21. http://www.nanotechproject.org/inventories/cons umer/analysis_draft/.

22. Parvin $D$ M, 'need for governing Nanotechnology Research and Development in Bangladesh', International Journal of Scientific and Engineering Research,4(11),2013,pp:179

23. https://www.researchgate.net/publication/25937 1153_Nanotechnology_and_Governance_in_Ba ngladesh

24. Meeting Minutes of Nanotechnology Committee in the of Science \& Technology, Bangladesh on the date 19.06.2013. 